\title{
A Technical and Business Perspective on Wireless Sensor Network for Manufacturing Execution System
}

\author{
Wei Xu, ${ }^{1}$ Zhixin Yang, ${ }^{2}$ and Xianbo Wang ${ }^{2}$ \\ ${ }^{1}$ School of Management, Henan University of Science and Technology, Luoyang 471000, China \\ ${ }^{2}$ Department of Electromechanical Engineering, Faculty of Science and Technology, University of Macau, Macau \\ Correspondence should be addressed to Zhixin Yang; zxyang@umac.mo
}

Received 9 May 2014; Accepted 21 July 2014

Academic Editor: Pak-Kin Wong

Copyright (c) 2015 Wei Xu et al. This is an open access article distributed under the Creative Commons Attribution License, which permits unrestricted use, distribution, and reproduction in any medium, provided the original work is properly cited.

\begin{abstract}
Motivated by the complex production management with difficulties in error-prone assembly system and inaccurate supply chain inventory, this paper designs a novel manufacturing execution system (MES) architecture for intelligent monitoring based on wireless sensor network (WSN). The technical perspective includes analysis on the proposed manufacturing resource mutual inductance method under active sensing network, appreciation technology of multisource information, and dynamic optimization technology for manufacturing execution processes. From business perspective, this paper elaborates the impact of RFID investment on complex product by establishing a three-stage supply chain model that involves two suppliers carrying out Stackelberg games (manufacturer and retailer). The optimal cost threshold values of technology investment are examined for both the centralized and the decentralized scenarios utilizing quantitative modeling methods. By analyzing and comparing the optimal profit with or without investment on WSN, this paper establishes a supply chain coordination and boosting model. The results of this paper have contributed significantly for one to make decision on whether RFID should be adopted among its members in supply chain. The system performance and model extension are verified via numerical analyses.
\end{abstract}

\section{Introduction}

With intensifying competition in the global market, higher requirements are put forward for manufacturing enterprises in terms of improving product quality and production efficiency, reducing production costs, reducing resource consumption, and so forth. Transparency, intelligence, and global optimization of production process become the development trend of manufacturing enterprises and provide new driving forces for the development of MES. At present, great process of MES has been achieved in terms of both theoretical research and industrial application. In particular, studies on key technologies such as integrable MES, reconfigurable MES, and real-time MES based on automatic identification technologies, and their applications in aerospace, automobile, iron, and steel, petrochemical industries, and so forth, provide technical support for monitoring and optimization of production sites and thus generate great application effects and economic benefits.
With increasingly complex and large scale of industrial production process and randomly changing production environmental factors, information of the production process presents multisource and massive features. However, due to lack of systematic solutions to effective automatic identification and access to real-time multisource information, there are phenomena of time-consuming collection, serious delay, proneness to errors, and so forth when getting multisource information. Meanwhile, during actual production, constant urgent tasks and frequent changes of plans, and so forth, bring serious phenomena such as low operational efficiency of implementation system, unsmooth process flow turnover, lack of effective control of work in process, and overstocked products. Due to lack of multilayered mapping relationships between multisource raw data and key manufacturing process monitoring links and dynamic and efficient integrated model, some key links of manufacturing process are difficult to be reflected timely and accurately. In addition, although existing workshop execution system can realize punctual 
issuance of daily workshop plans, upper management is difficult to achieve effective control and dynamic coordination and optimization of manufacturing execution process and lacks overall analysis, reasonable and efficient dynamic optimization strategies, and methods of production process due to the lack of item level production scheduling prediction and timely feedback of manufacturing information.

With the penetration of the WSN thought into the manufacturing field, the development process of manufacturing enterprises has transferred from a traditional invisible mode into a multidimensional transparent ubiquitous sensing mode. RFID (radio frequency identification) is a recent technology that has been well adopted as real-time manufacturing object monitoring and tracking technique that enables wireless sensor network [1]. RFID technology could simultaneously acquire multiple tags signal and trace individual moving trajectory of manufacturing objects without human interactions. Such manufacturing execution system equipped with information sensing technology, as the driving force, could promote vigorously manufacturing system to be developed in global, information, intelligent, and green direction.

The remainder of this paper is organized as follows. In the following section, we give a quick idea of the topics covered in the literature review. In addition, literatures related to this study will be reviewed. In Section 3, we introduce intelligent monitoring MES based on wireless sensor network. From a technical perspective, we analyze the system architecture, complex event processing, quality information monitoring, and technology resources in detail. The RFID investment model analysis and the main results of this research are presented in Section 4. The numerical analysis is examined in Section 5 and we offer a summary, together with a critique of the model, and a direction for future research in the final section.

\section{Literature Review}

With the emerging, development, and application of wireless sensor network in manufacturing area, ubiquitous information fusion and processing methods, together with RFID technology, are greatly changing the operation and management mode of existing manufacturing system, through which some new management ideas and methods are generated. In the following part, we give a quick idea of the topics covered, and the literatures related to this study will be reviewed. We survey the relevant works in three perspectives: we first go through the potential benefits and common applications of RFID technology, then review RFID investment on supply chain with contracts on two- or three-level supply chain coordination, and finally study the development of manufacturing control system based on RFID for industrial applications and dynamic logistics process.

Huang et al. [2, 3] reported that wireless devices and wireless network technologies such as RFID, Bluetooth, ZigBee, and WiFi can be combined with target objects and other production resources in manufacturing system and be allocated as smart objects to realize closed-loop, real-time, and accurate control of manufacturing system, called advanced wireless manufacturing system. Jun et al. [4] put forward the concept of closed-loop PLM, which is believed to be a new business strategy in which product data, information, and knowledge are obtained via smart objects. Product data and knowledge management (PDKM) system was adopted in order to manage product lifecycle activities effectively. Ubiquitous product lifecycle management (PLM) can ensure that all relevant product lifecycle information can be obtained and information exchange at all stages can be realized via ubiquitous technology.

The applications of RFID technology in Taiwan retail industries were analyzed to reveal its advantages and complexity as well as supply chain integration [5]. Attempts of applying RFID and agent on manufacturing control and coordination system were studied [6]. A RFID-related resource management system was reported which helps users select the most appropriate resource package by mining and analyzing sample database in order to handle inventory operation order [7]. A model based on branch-and-bound method has been designed with the most appropriate forklift driving distance, which can be selected to reach optimal configuration. Chow et al. [8] studied a logistics operation system based on RFID and Web technologies, which could reduce inventory level and out-of-stock products through visualization of logistics process, improve delivery efficiency, and successfully realize benefit maximization among cooperators in the upstream and downstream supply chains. A phenomenon of inventory error due to commodity theft was studied through evaluation of the influence of RFID on inventory accuracy [9]. To track products embedded with tags in large-scale supply chain effectively, a product tracking system which could collaborate with EPC network and network service of supply chain-oriented RFID data management is described. The product tracking process of this system was compared between actual product paths and planned paths. A product search algorithm based on reinforcement learning technology in order to localize effectively products which deviate from the original paths was then proposed. Roh et al. [10] set the expected revenue as one of the main motivations of using RFID technology, and the core expected revenue of RFID includes cost reduction, increased visibility of supply chain, and promotion of process reorganization. It was indicated that revenue, costs, and technical knowledge could determine the adoption of RFID technology, while RFID cost-benefit analysis could directly judge the feasibility of RFID deployment [11].

As a relatively new technology, RFID arouses the interest of researchers and supply chain enterprises and many research results have explored the impact of RFID technology on the processes of enterprise supply chain management. Considering that the investment in RFID-based system is quite high, the method aiming at evaluation of the technique investment cost and possible income so as to provide decision-making reference for potential RFID application in government and enterprise is, however, still an open problem not well solved. The research field in RFID application is wide, and the research status is collected from the following perspectives. Sarac et al. [1] studied the application of RFID technology in supply chain management and its impact on supply 
chain management and summarized different methods of analysis, such as model analysis, simulation, case study, and return on investment analysis. In consideration of the same problem, two other research efforts and analysis works from the perspective of the whole supply chain were also reported $[12,13]$. We will summarize the impact of research status of RFID from the perspective of various links of supply chain management. Combining RFID technology with various computer analog technologies was also be studied and was used in the supply chain system $[14,15]$. The adoption of RFID technology in container depot [16], in production process of automobile suppliers [17], and in resource management system used in the selection of warehouse parcel $[7,18]$ was reported, respectively. Huang studied the application of RFID technology in the real-time management of work-in-process inventory of the manufacturing shop [3]. The result revealed that RFID had been preliminarily applied in the production process management of a large automobile enterprise.

As a typical industry facing unprecedented market competition environment, automotive enterprises are commonly proposed to adopt RFID devices. The consumption demand in automobile market tends to be increased dramatically under diverse customer requirements. Besides, the consumers requests to receive product are usually at an individually preferred time and place at the lowest price and fastest speed, which in turn greatly increase the uncertainty of market demand [19]. The vehicle assembly enterprises integrate and coordinate the supply chain, form strategic partnership, innovate for supply chain logistics pattern, and coordinate and control parts suppliers and distributors as well as the relationship among production, supply, and sale. Additionally, they are the hub to connect upstream and downstream enterprises in the supply chain and play a leading role of driving and controlling the supply chain [20]. The automobile components and parts cost accounts for 60 $70 \%$ of total automobile cost. Cutting down the parts cost is an issue widely focused on by automobile manufactures. Global procurement is a strategic change in supply chain management adopted by vehicle manufacturers in order to reduce the cost. There are more than thirty thousand automobile parts. Various automobile components and parts manufacturers are distributed across the world. In order to save cost and improve the quality, vehicle assemblers adopt global production processes where individual components are manufactured globally and vehicle assemblers integrate the parts. Information technology is applied to plan information flow, capital flow, and logistics in automobile supply chain and construct e-commerce purchase and sales platform [21]. Through application of various advanced information technologies, each member in the supply chain can timely and effectively gain the information required so as to make timely response and meet customers' needs.

The utilization of RFID technology is beneficial to the manufacturing enterprise to provide demand information timely and accurately. For the supply chain system with various raw materials, parts, and components, the items can be identified effectively by implementing the RFID technology to make the raw material supply process faster and more accurate. Furthermore, as the RFID tag contains detailed information including production material, date of manufacturing, manufacturer, and test time, the manufacturer can trace the purchasing source of raw materials easily, which is beneficial to strengthen the control of supply channel. It was found that the RFID label of each product would be beneficial to the profit of the retailer, but not to the manufacturer, which will reduce the manufacturer's profit [22]. Cost effectiveness is a factor to be used to evaluate whether the RFID device shall be reused. Tajima [23] verified that the application of RFID technology in manufacturing and assets management can obtain good returns on investment in a closed-loop system. The ROI research about the RFID implementation in the early stage focusing on the direct income analysis of RFID technology, such as increase of sales quantity and reduction of product loss [24], further studied the problem concerning the potential income of RFID technical investment. RFID can improve customer satisfaction; however, it is difficult to quantify this potential income due to the limitation of ROI method. A feasible research on the three-level supply chain involving the manufacturer, distributor, and retailer was studied from an overall perspective. Questionnaire survey was used as input for carrying out a quantitative evaluation of the impact of the RFID and EPC systems on the supply chain of fast moving consumer goods [14]. The research results have shown that this technology is not equally profitable to each member of the supply chain, where the label on the tray is beneficial to each party of the supply chain while the label on the container will reduce the income.

The targeted research objects in this paper is the threelevel manufacturing supply chain. Considering the characteristics of different products, three-level enterprises are deemed to be supplier, manufacturer, retailer, distributor, and agent. Munson have conducted research on how to reduce the cost of "S-M-R" supply chain with quantity discounts contract and taken into account of cost reduction benefit to downstream enterprises from the manufacturers' perspective [25]. Although they have studied the three-level inventory problem based on a classical EOQ model, the system ordination is realized by saving production cost and inventory expense under a certain demand. Discussion on a multiechelon cooperation model and how to optimize the relation between suppliers by using the new technology occurred in e-commerce and supply chain management [26]. Their research focused on the enterprises relation and divided it into three layers: the first layer is the primary level realized by ERP or E-mail and internet; the second layer is the data integration in the supply chain management tool, which integrates the latest demand information and supplier information; and the third level combines with the multiechelon suppliers by cooperation plan and prediction. Due to the complexity of supply chain in reality, a model containing multisuppliers and the research showing that the input of one supplier may increase the profits of other suppliers were analyzed [27]. The inventory reallocation problems have been analyzed via adopting game theory [28]. A supply chain having multiple upstream enterprises was reported [29], which included different suppliers providing parts and components for manufacturers. Therefore, when the parts and components are different, the production 
quantity will be restricted; meanwhile, some components will be wasted. In this case, all suppliers are inclined to provide less parts and components. They have designed multiple contracts to stimulate the amount of supplies of all suppliers, so as to increase the output of manufacturers. The wholesale price contract in the multiple competitive retailer model was analyzed [30]. This paper will depict the effect on changes in production and sales by using new technologies including cooperation tool and e-commerce.

\section{Intelligent Monitoring MES Based on Wireless Sensor Network}

MES based on WSN put forward in this paper refers to interconnection and mutual inductance of various kinds of manufacturing resources formed by introducing various sensing technologies to traditional MES. Based on this, this system can realize active sensing, dynamic optimization, and online monitoring of production process of manufacturing execution of the entire process from production order placing to product completion by optimal management technology driven by real-time multisource manufacturing information and can realize efficient operation of manufacturing execution process through appreciation of decision-making technologies of multisource information.

Compared with traditional MES, the core advantages of MES based on WSN are to get richer information through more accurate process status tracking and more complete real-time data, have more scientific management of production sites under rational decisions, discover abnormalities actively through network technologies distributed in physical manufacturing resources combined with integration of multisource information and complex information processing technology, and carry out comprehensive monitoring and optimization of production process by real-time multisource manufacturing data.

3.1. System Architecture. Based on the above system concepts, this paper designs one type of MES architectures based on sensor network as shown in Figure 1. This architecture is mainly consisting of mutual inductance of things in WSN, object perception, information integration, application services, and data service center.

The mutual inductance of things in WSN is mainly oriented to physical manufacturing resources layer for collection of multisource manufacturing data. The interconnection and mutual inductance of physical manufacturing resources are realized by configuring various sensors and wireless networks and thus ensure real-time, accurate, and reliable access to multisource information of manufacturing processes. Object perception module begins with the management of a variety of heterogeneous sensor groups. It could provide services for real-time manufacturing activities in which various sensors actively sense and transmit various manufacturing resources in the context of heterogeneous communication network.

Information integration layer is to serve for converting multisource and scattered site data originated from heterogeneous sensors into standard manufacturing information that can be used in decision-making of manufacturing execution process on the basis of getting production process manufacturing data and finally integrating and converting into standard manufacturing information that serves directly for manufacturing execution process monitoring and optimization.

Application services are mainly for different users of manufacturing enterprises. From the perspective of using multisource information of production sites, it could realize optimal management of manufacturing execution process, transparent information, real-time process sensing, and dynamic optimal management of network manufacturing execution process. The services that could be provided include real-time manufacturing resources monitoring services, dynamic production tasks scheduling services, optimal materials distribution services, manufacturing process monitoring and coordination services, real-time processing quality monitoring and diagnosis services, and services of integration with other systems. Data service center is the centralized information provider that provides services for the operation of the internet of things (IOT) and MES from perspectives of data, information, and knowledge. The submodules of data service include sensor network configuration information, sensor registration information, real-time information, manufacturing resources information, reliability knowledge base for system decision-making services, data integration rules base, and production management knowledge base.

3.2. Complex Event Processing. The basic concept of complex event processing (CEP) is to abstract massive data generated by WSN into events according to certain rules. The processed events will be aggregated into high-level information that users are interested in according to a certain mode. Data dynamically generated by WSN may be associated with intrinsical errors, while the real operation situation of enterprises is included. Due to the limitation on communication bandwidth, it is impossible and unnecessary to transmit all such massive data to business management software, and a middleware system is needed to process such massive data.

WSN middleware is used to process data communication and data representation between intelligent devices (such as between readers and sensors) and enterprise application systems or other middleware systems. The architecture of which is shown in Figure 2. This architecture is divided into model parts, engine parts, and functional parts of intelligent object middleware. Functional parts mainly include physical layer, event processing layer, information conversion layer, and information presentation layer. Physical layer is mainly used for abstract representation of system hardware and protocols. Event processing layer is mainly used to identify user demand information from massive time-series data and provide such data for users by appropriate measures, which include filtering, data recovery and supplement, event aggregation, CEP, semantic event mining, and semantic data processing. In addition, data persistence is also included in two ways of local cache and message queue. Information conversion layer could convert information into formats required by customer application system. The information presentation layer mainly shows information that users get 


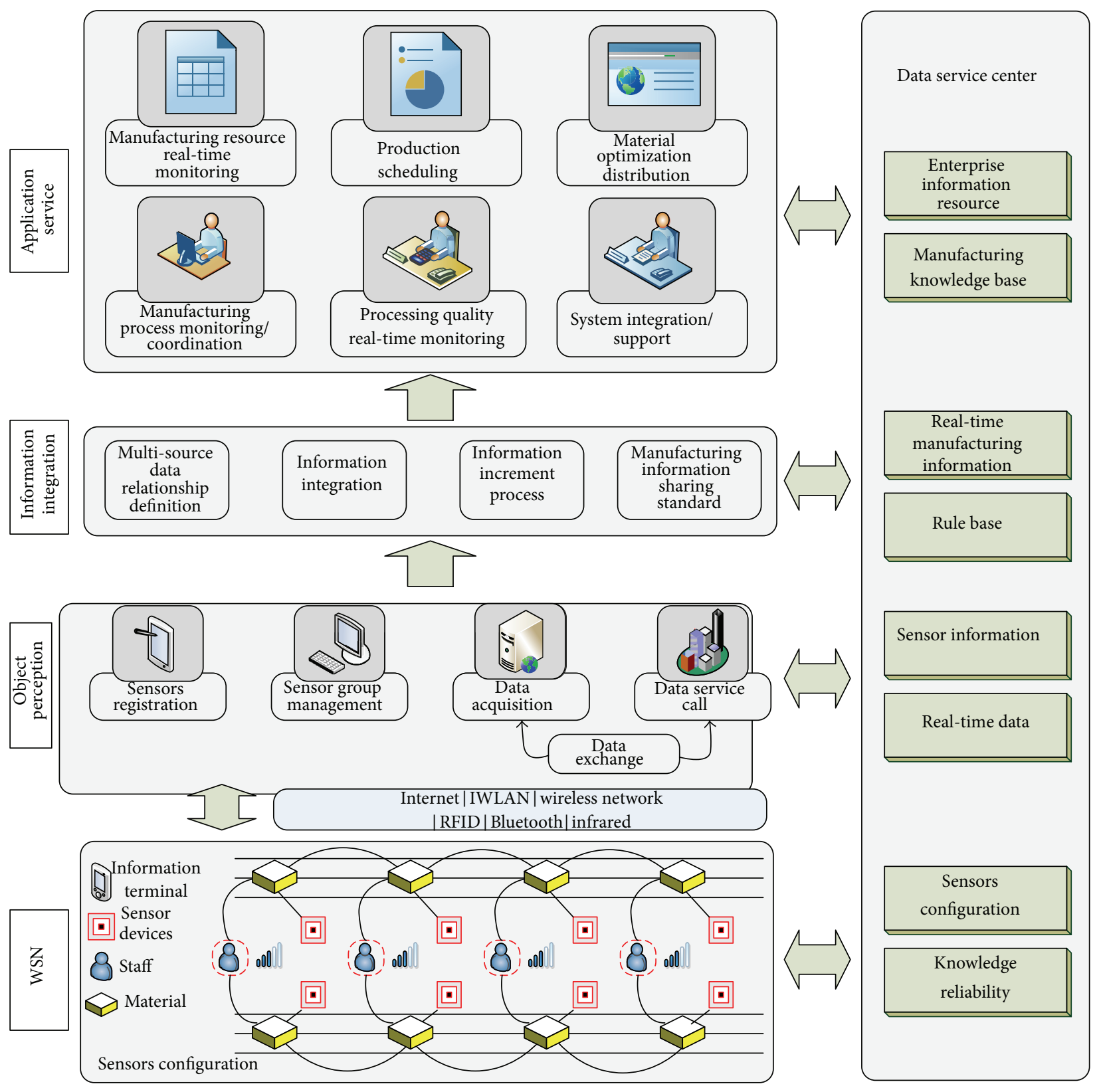

FIGURE 1: Architecture of MES based on WSN.

in different ways, which basically include manufacturing enterprise applications (such as MES, ERP, SCM, and CRM), enterprise portal, and database systems.

\subsection{Production Process Quality Information Monitoring and} Localization. Sensing, monitoring, full tracking, and localization of production process, as well as quality information, are the key to ensure and enhance product quality. Figure 3 shows implementation framework of sensing, monitoring, tracking, and localization technologies of production process quality information in MES based on WSN. It involves two aspects of production process online quality monitoring and diagnosis and full tracking and localization of multiple manufacturing resources quality information driven by quality problems.
Quality problems full tracking and localization model is shown in the upper part of Figure 3, and this system conducts information tracking and localization of various factors of different locations that may lead to such quality problems, such as tracking and localization of equipment quality information based on historical data of operating conditions of production equipment, tracking and localization of all completed other process quality information related to process of this problem based on manufacturing BOM, and tracking and localization of manufacturing process related to the problems. Besides, this system realizes view of quality tracking and localization of full information by standard tracking and localization information expression templates, achieves diagnosis and tracking and localization 


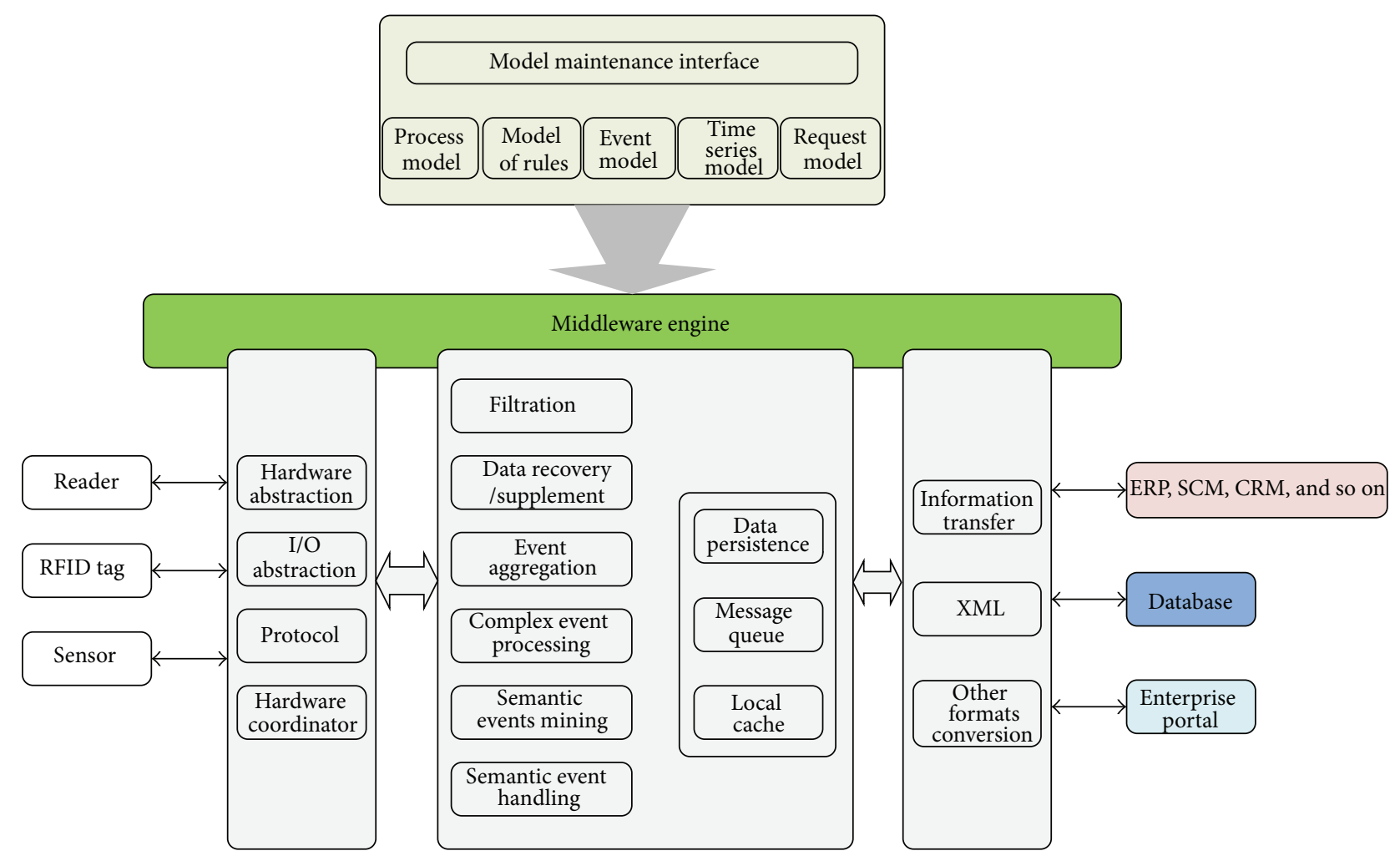

Figure 2: Architecture of the WSN middleware system.

of production process quality information, and provides full quality information for analyzing various different manufacturing resources involved in quality problems, rapid screening, and targeting of manufacturing resources that are the most likely to cause quality problems.

As shown in the base layer of Figure 3, workpiece production process quality involves diverse and complex factors, such as abnormal equipment operating conditions, wear of tool, localization errors of clamps, and accumulation of processing errors caused by multiple processes of products. Thus, real-time quality information templates based on XML are used to classify and extract all relevant data that causes processing quality problems. The acquired data will be analyzed and compared with real-time information comprehensively by dynamic process capability evaluation. Other tools including intelligent operating condition monitoring based on machine learning methods, analysis of coupling effects among quality information, and quality control charts will be applied through monitoring various operating conditions in manufacturing equipment, such as vibration and noise signal. The geometrical properties of workpiece in terms of dimension, tolerance, surface features, positional error, and so forth, could also be acquired as indicators for real-time quality monitoring. Online diagnosis of quality information of production process is carried out by building mathematical neural network models, such as SVM and ELM, and applying statistics methods for feature extraction.

3.4. Analysis of Technology Resources. Technology resources are elaborated during deployment of ideas and methods of the selected technologies for building real-time networked manufacturing information system. The involved processes in networked manufacturing resources include production processes, active sensing, and dynamic optimization approaches. To manage such interconnected manufacturing resources in a systematic way, mutual inductance technology based on sensor networks is the premise and foundation for realizing active sensing for real-time information exchange in MES. Multisensor technology is required to be applied on traditional manufacturing resources for the collection of multisource information involved in manufacturing process. It could provide technical support for realizing real-time mutual inductance of multisource manufacturing information. Multisource information active sensing of production process is an important way for MES based on WSN to get actively dynamic information of manufacturing execution processes. In addition, it enables MES to provide aggregation information for dynamic optimization decisions of manufacturing execution process.

Figure 4 shows the architecture of mutual inductance technology of manufacturing resources based on sensor networks, including sensor network optimal configuration and intelligent manufacturing resources modeling. Equip corresponding sensing devices for different manufacturing resources (such as people, equipment, materials and tools), and thus manufacturing resources have certain logical behavioral capability and could sense changes of surrounding manufacturing environment actively. The diagram could reflect he real-time operating condition which is with fluctuating manufacturing resources and environmental information. 


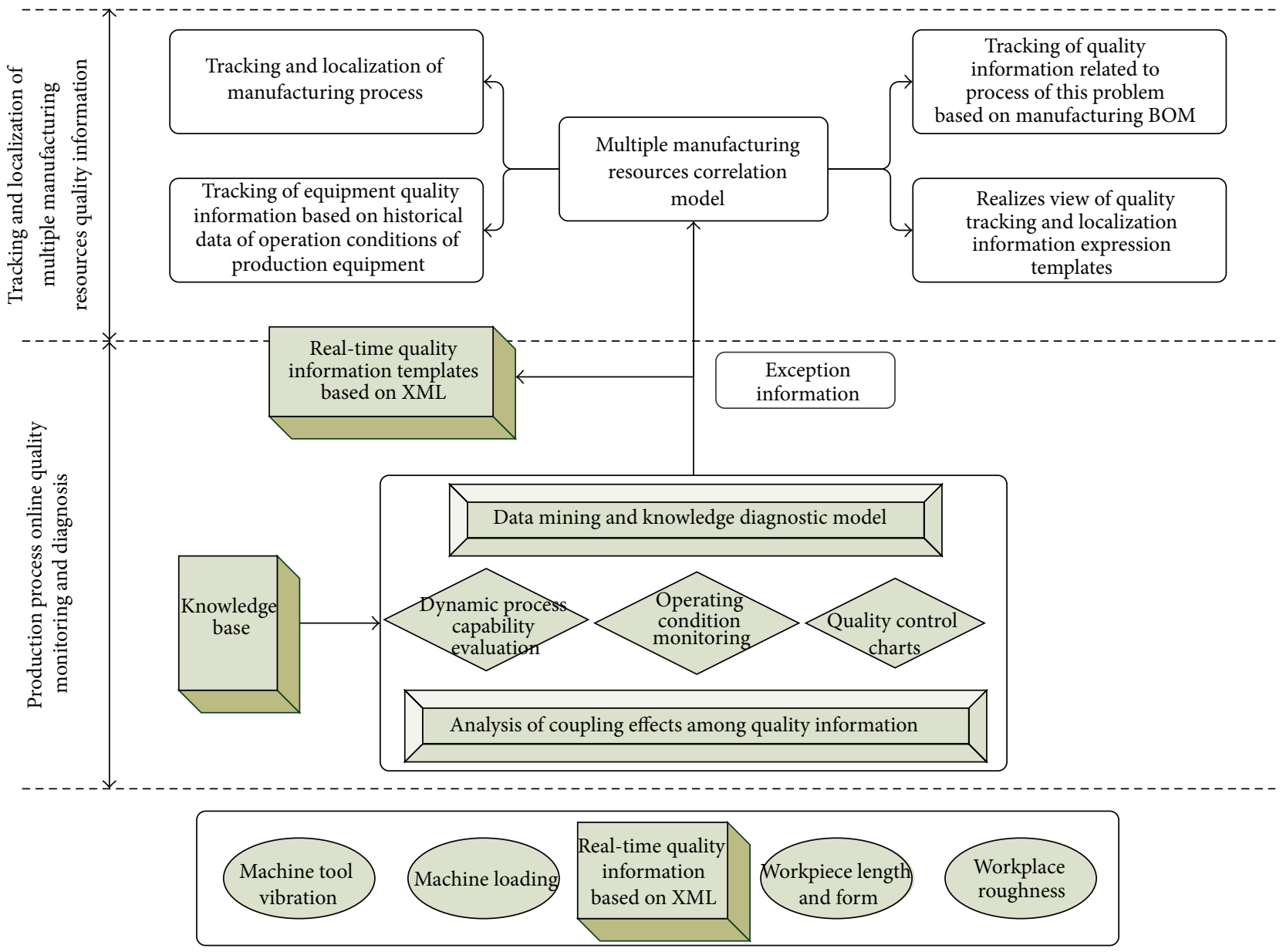

FIGURE 3: Implementation framework of production process quality information monitoring and localization in MES.

In the example of using RFID sensing device in workshop, staffs embedded with RFID tag, trays, and manufacturing workstations installed with RFID readers and sensors as measurement equipment can be treated as intelligent manufacturing resources. Among these, manufacturing resources equipped with RFID readers can be seen as intelligent manufacturing resources with sensing ability. Manufacturing equipment installed with RFID readers can sense the active state of those sensible intelligent manufacturing resources (staffs, WIPs, trays, and materials, etc., equipped with RFID tag), that are equipped with tag of RFID, within a specified range of distance. Meanwhile, with multiagent, intelligent manufacturing resources can realize their business logic and interaction and coordination with other intelligent manufacturing resources according to predefined workflow model, as well as sense and analyze possible or determined dynamic conditions in manufacturing environment.

\section{Analysis of RFID Investment Model}

4.1. Modeling Framework. In this section, we would evaluate and analyze the impact of RFID among three-level supply chain partners involving multiple components and parts suppliers. The relevant supplier, as we know of vehicle manufacturer, and multiple automotive $4 \mathrm{~S}$ stores with an independent relation. The structure of the three-level automotive manufacturing supply chain is shown in Figure 5. They pursue the maximum profits, respectively. Consequently, the main issue focuses on which member takes the priority to employ RFID. Then, two approaches of the integrated RFID investment policy and individual RFID investment policy are presented. As in the previous references, the optimal benefits of using RFID by numerical solutions are also proposed.

The summary of notations used in this paper is shown at the end of the paper, where $p_{m}+c_{m}<w_{m}<w, p_{m}>C\left(\Gamma_{s}\right)$.

RFID technology can improve customer service level effectively. Considering business strategic positioning, with $4 \mathrm{~S}$ stores constantly entering the automotive accessory industry, because of the great number, remoteness, and decentrality of automotive $4 \mathrm{~S}$ stores, using information technology to improve the competitiveness of after-sale service directly affects the final sales quantity. Generally, demand increases with the increase of technology investment. However, the marginal demand of RFID investment decreases. Therefore, we assume that the function of total market demand is

$$
D\left(\Gamma_{r}\right)=\rho_{1} \Gamma_{r}^{k_{1}}+d
$$




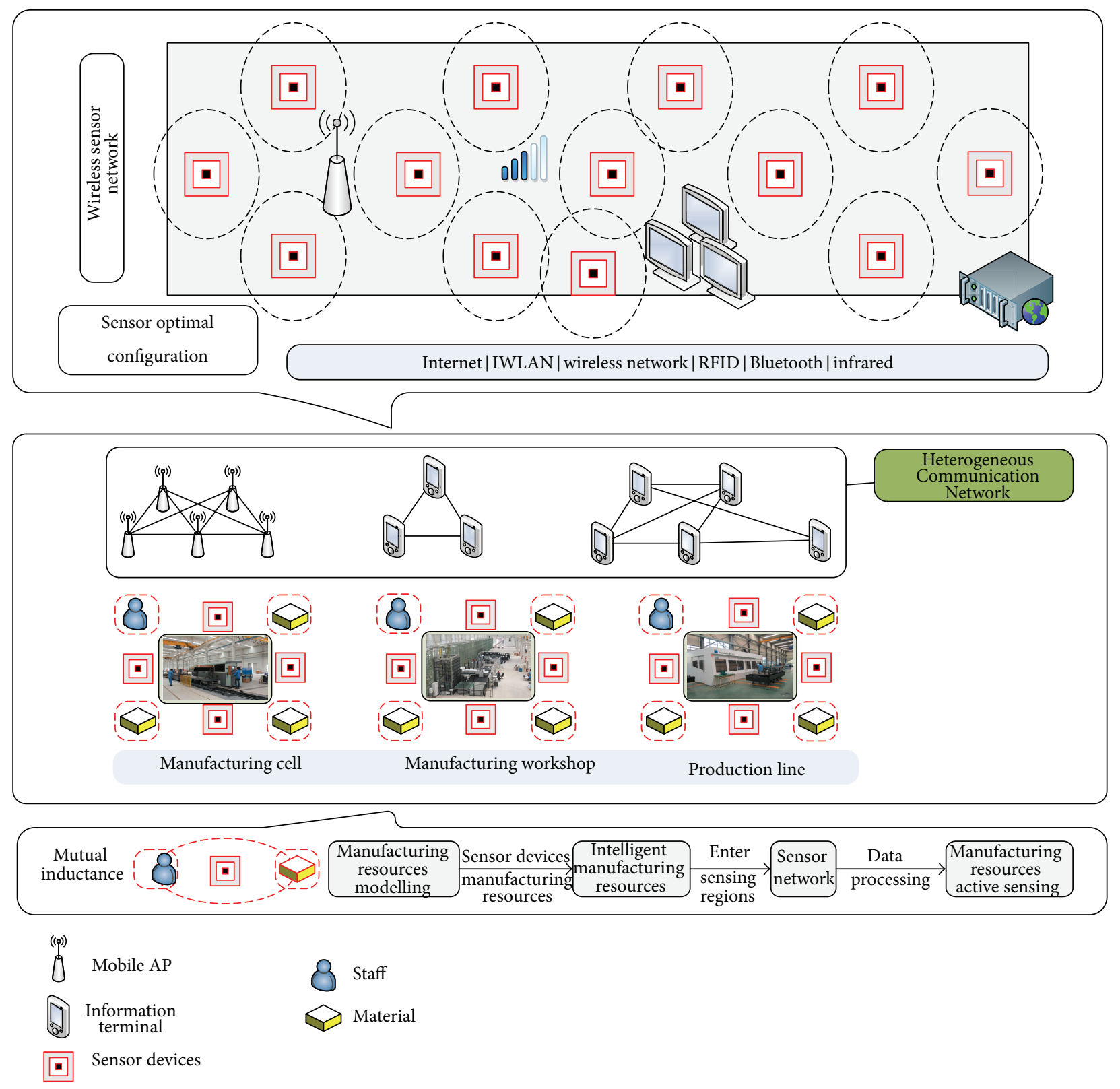

FIGURE 4: Architecture of mutual inductance technology of manufacturing resources based on sensor networks.

where $\rho_{1}$ is the RFID investment sensitivity coefficient, $\rho_{1}>$ $0 . k_{1}$ is the RFID investment flexibility of the incremental cost of the unit product, $0<k_{1}<1$. RFID's many successful application cases are as follows: a Benz $4 \mathrm{~S}$ distributor in Atlanta and Guangzhou Honda Motor Company now uses RFID system to provide personalized services for customers and vehicle identification. When a customer enters the automotive $4 \mathrm{~S}$ store, the owner information and maintenance record stored in the automotive can be obtained through the reader, thus greatly accelerating the after-sale service process and improving sales performance.

Meanwhile, to realize visibility and flexibility of assembly manufacturing system, the components and parts suppliers have made considerable investments in supply chain management information system. RFID technology can be applied to automotive supply chain to improve the visibility of the manufacturing system and thus positively influence the supply chain. Survey research institute ABI Research considers that vehicle components suppliers and manufacturers can benefit significantly from RFID technology, especially in logistics supply chain tracking and assembly production line. Thus, we assume that a unit product needs a unit raw material (or semifinished products, components, and parts). Generally, the unit product cost decreases with the increase of investment of RFID, but the marginal cost of investment decreases. Therefore, the function of the unit product cost is

$$
C\left(\Gamma_{s}\right)=c_{s}-\rho_{2}\left[\frac{\Gamma_{s}}{D\left(\Gamma_{r}\right)}\right]^{k_{2}},
$$




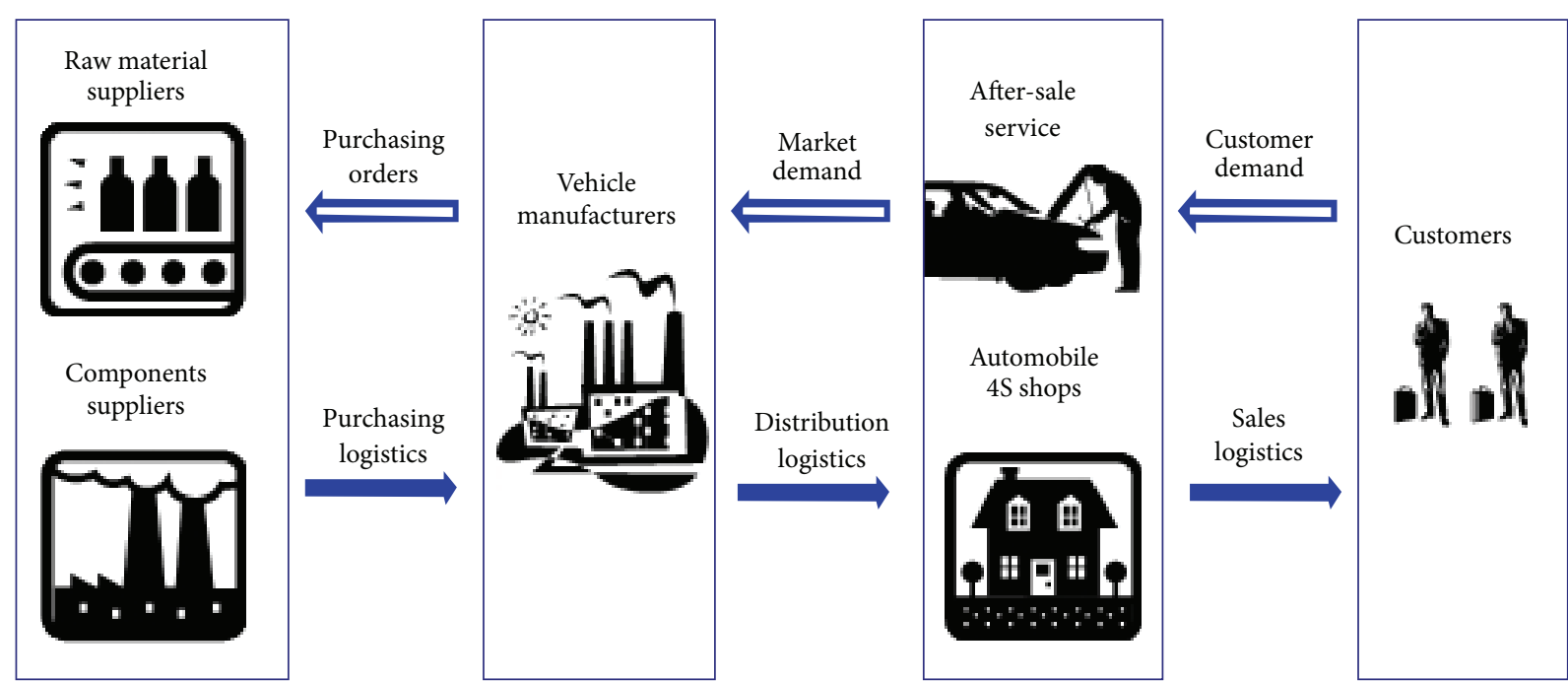

FIGURE 5: Structure of automotive manufacturing supply chain.

where $\rho_{2}$ is the RFID investment sensitivity coefficient of the unit product cost, $\rho_{2}>0 . k_{2}$ is the R\&D investment flexibility of the unit product incremental cost, $0<k_{2}<1$.

4.2. Integrated RFID Investment Policies. In this section, we consider all members in the three-level manufacturing supply chain, including multiple suppliers, one manufacturer, and multiple stores, all of which aim to maximize the profit of the overall supply chain during centralized decision-making. At the moment, this system is similar to a three-stage supply chain system composed of one supplier, one manufacturer, and one retailer. Therefore, we focus on analyzing the following three situations: the profit of the whole supply chain when only the components suppliers or $4 \mathrm{~S}$ stores invest RFID technology, and the profit of the manufacturing supply chain with all members implementing technology investment.

\subsubsection{Components Suppliers Implement RFID Technology. The} global development tendency of the automotive industry is that multinational companies conduct a unified layout for production and marketing on a global scale to establish a global production system. For example, the product selfmaking ratio of various major multinational motor companies is only about $30 \%$, for example, Ford 38\%, GM 30\%, and Toyota $22 \%$. Original equipment manufacturers are more and more inclined to produce only a few key components and parts of the automotive. For standard general automotive components and parts, suppliers are selected by comparison on a global scale according to the QCDD or QCDS principle (quality, cost, delivery, design, or service). It is conducive to the implementation of global procurement using global resources. Global procurement has become a shortcut for automobile enterprises to rapidly increase competition, which allows enterprises to complement each other's advantages and gain joint development. Meanwhile, with the rapid development of information technology, RFID application in the enterprise management of the universal realization of automobile components and parts suppliers using RFID technology-based information management is imperative.

If components suppliers make significant investments in information technology and innovation, the general expected profit of the whole supply chain for the centralized decision making system can be expressed as

$$
\begin{aligned}
\Pi\left(\Gamma_{s}\right) & =d \cdot\left[w-c_{m}-C\left(\Gamma_{s}\right)\right]-\Gamma_{s} \\
& =d \cdot\left[w-c_{m}-c_{s}-\rho_{2}\left(\frac{\Gamma_{s}}{d}\right)^{k_{2}}\right]-\Gamma_{s} .
\end{aligned}
$$

The optimal RFID investment for components suppliers and the optimal profit are, respectively, given by

$$
\begin{gathered}
\bar{\Gamma}_{s}^{*}=\left(\rho_{2} k_{2}\right)^{1 /\left(1-k_{2}\right)} d, \\
\Pi\left(\bar{\Gamma}_{s}^{*}\right)=d \cdot\left[w-c_{m}-c_{s}-\rho_{2}\left(\frac{\bar{\Gamma}_{s}^{*}}{d}\right)^{k_{2}}\right]-\bar{\Gamma}_{s}^{*} .
\end{gathered}
$$

4.2.2. $4 S$ Stores Invest RFID Technology. In the practical operation of $4 S$ stores, the phenomenon of automobile spare parts in short supply often occurs, which not only directly influences the profit of automotive $4 \mathrm{~S}$ stores but also reduces their service level and customer satisfaction, thus influencing consumers' loyalty to an automobile brand. When products are out of stock, $14 \%$ of customers are lost because of dissatisfaction with the service of the original brand, and $68 \%$ of customers change the brand while buying a car for the second time. To improve the service level and reduce or avoid the shortage of automotive components and parts, inventory should be increased. However, the larger the inventory, the higher the inventory cost; that is, inventory cost and service level are conflicting.

We can solve the problem above using RFID for enterprises well. A RFID system provides accurate information of the current inventory and contributes to monitoring and managing products in real time. 
According to the above analysis, the profit function of the whole supply chain can be written as

$$
\begin{aligned}
\Pi\left(\Gamma_{r}\right) & =D\left(\Gamma_{r}\right) \cdot\left(w-c_{m}-c_{s}\right)-\Gamma_{r} \\
& =\left(\rho_{1} \Gamma_{r}^{k_{1}}+d\right) \cdot\left(w-c_{m}-c_{s}\right)-\Gamma_{r} .
\end{aligned}
$$

The optimal RFID investment for automotive $4 \mathrm{~S}$ stores and the optimal profit are, respectively, such that

$$
\begin{gathered}
\bar{\Gamma}_{r}^{*}=\left[\rho_{1} k_{1}\left(w-c_{m}-c_{s}\right)\right]^{1 /\left(1-k_{1}\right)}, \\
\Pi^{*}\left(\bar{\Gamma}_{r}^{*}\right)=D\left(\bar{\Gamma}_{r}^{*}\right) \cdot\left(w-c_{m}-c_{s}\right)-\bar{\Gamma}_{r}^{*} .
\end{gathered}
$$

4.2.3. All Members Use RFID Technology Simultaneously. The expected profit of the whole supply chain with all members implementing RFID is as follows:

$$
\Pi\left(\Gamma_{s}, \Gamma_{r}\right)=D\left(\Gamma_{r}\right) \cdot\left[w-c_{m}-C\left(\Gamma_{s}\right)\right]-\Gamma_{s}-\Gamma_{r} .
$$

Proposition 1. The optimal investment costs of components and parts suppliers for R\&D and $4 S$ stores, respectively, for product promotion in the centralized system with RFID technology input are

$$
\begin{aligned}
\Gamma_{r}^{*}= & \left(\rho_{1} k_{1}\right)^{1 /\left(1-k_{1}\right)} \\
& \cdot\left[w-c_{m}-c_{s}+\left(1-k_{2}\right) \rho_{2}{ }^{1 /\left(1-k_{2}\right)} k_{2}{ }^{k_{2} /\left(1-k_{2}\right)}\right]^{1 /\left(1-k_{1}\right)}, \\
\Gamma_{s}^{*}= & \left(\rho_{2} k_{2}\right)^{1 /\left(1-k_{2}\right)} \cdot\left[d+\rho_{1}\left(\Gamma_{r}^{*}\right)^{k_{1}}\right] .
\end{aligned}
$$

The maximum profit of the overall manufacturing supply chain system is

$$
\Pi^{*}\left(\Gamma_{s}^{*}, \Gamma_{r}^{*}\right)=D\left(\Gamma_{r}^{*}\right) \cdot\left[w-c_{m}-C\left(\Gamma_{s}^{*}\right)\right]-\Gamma_{s}^{*}-\Gamma_{r}^{*} .
$$

For proofs, see the appendix.

\subsection{Individual RFID Investment Policies}

4.3.1. Game with Perfect Information among Multiple Components Suppliers. To encourage components suppliers to implement R\&D investment under the decentralized decision-making, we assume that the vehicle manufacturer's purchasing policies for $M$ upstream ones are as follows.

(i) When all components suppliers do not employ RFID technology, that is, $\Gamma_{s}^{i}=0$ for each supplier, each one can obtain $1 / M$ of the total demand share.

(ii) When all components suppliers implement RFID $\mathrm{R} \& \mathrm{D}$ investment, for the $i$ th components supplier $\left(\Gamma_{s}^{i}>0\right)$, the share of vehicle manufacturer demand obtained by the $i$ th supplier is $\Gamma_{s}^{i} \sum_{i=1}^{M} \Gamma_{s}^{i}$.

(iii) If some components suppliers invest RFID technology, while some others do not, those not investing will not get demand orders, and the vehicle manufacturer will allocate demand orders according to the investment share $\Gamma_{s}^{i} \sum_{i=1}^{a} \Gamma_{s}^{i}$ ( $a$ is the number of enterprises making an investment, $0<a<M)$. (iv) As the number of components suppliers $M>$ 1 and each supplier has a small scale and weak R\&D strength, each supplier will consider investment risk when adopting RFID technology. Therefore, the vehicle manufacturer can provide subsidy for each supplier. We assume that all suppliers are risk neutral, each supplier's probability of technical R\&D success is $\theta$, the subsidy rate is $\beta$, and all suppliers have the same unit product $\operatorname{cost} c_{s}$. After R\&D investment, the expected value of the unit product cost by supplier $i$ is $C^{i}\left(\Gamma_{s}\right)=c_{s}-\theta \rho_{2} \sum_{i=1}^{M} \Gamma_{s}^{i} D\left(\Gamma_{r}\right)^{k_{2}}$. With the optimal RFID investment of the system, it can certainly succeed in research and development.

The vehicle manufacturer's purchasing price for $M$ components suppliers is $p_{m}$. As technical superiority might reduce the product cost and produce $R \& D$ subsidy and more market shares, rational components suppliers should invest RFID. Therefore, we mainly consider this situation. All suppliers play a static game of perfect information, and each supplier chooses the investment that can maximize its own profit.

Analyzing through the way as aforesaid, it is known that the components suppliers struggle to get more orders from the vehicle manufacturer and constantly reduce the cost by information technology and compete in RFID technology $\mathrm{R} \& \mathrm{D}$ investment. As in an arms race, the result is that each supplier has the same investment. Meanwhile, when the total RFID investment cost of this supply chain system is a certain value, the total profits of components suppliers' will be maximized. Otherwise, if the RFID cost is lower than this definite value, costs may still be reduced. Additionally, if the technology investment is higher than this definite value, it wastes resources since the cost has reached the liminal value. Given this complete information static investment game, each component's supplier will choose $1 / M$ of the optimal system investment cost to segment the vehicle manufacturer demand.

Proposition 2. The optimal RFID investment cost of components suppliers in decentralized decision-making is $\Gamma_{s 1}^{*}=\Gamma_{s 2}^{*}=$ $\cdots=\Gamma_{s}^{*} / M$, if and only if the components' suppliers satisfy the following constrained equations:

$$
\begin{gathered}
\Gamma_{s 1}=\Gamma_{s 2}=\cdots=\Gamma_{s M}, \\
(M-1)\left(p_{m}-c_{s}\right)\left(\rho_{1} \Gamma_{r}^{k_{1}}+d\right) \\
+\theta \rho_{2}\left(M-1+k_{2}\right)\left(\rho_{1} \Gamma_{r}^{k_{1}}+d\right)^{1-k_{2}} \\
\times\left(\sum_{i=1}^{M} \Gamma_{s i}\right)^{k_{2}}-M(1-\beta) \sum_{i=1}^{M} \Gamma_{s i}=0 .
\end{gathered}
$$

The optimal RFID investment cost is a perfect Nash equilibrium 
4.3.2. Game with Perfect Information among Multiple Automotive $4 S$ Stores. If the downstream $4 S$ stores use RFID technology to quickly pick up any demand changes and enable them to tweak their strategies accordingly, RFID will help them reduce logistical cost, improve operation efficiency, enhance customer satisfaction, and increase the market demand. Thus, we assume that the vehicle manufacturer's wholesale policy for retailers is as follows.

(i) When all $4 \mathrm{~S}$ stores do not implement RFID investment, that is, $\Gamma_{r}^{j}=0$, each $4 \mathrm{~S}$ store can obtain $1 / \mathrm{N}$ of the total market demand share.

(ii) When all $4 \mathrm{~S}$ stores invest RFID technology for product promotion, that is, $\Gamma_{r}^{j}>0$ for the $j$ th $4 \mathrm{~S}$, the share of the total market demand obtained by the $j$ th $4 \mathrm{~S}$ stores is $\Gamma_{r}^{j} / \sum_{j=1}^{N} \Gamma_{r}^{j}$.

(iii) If some $4 \mathrm{~S}$ stores adopt RFID, while some others do not, those not investing RFID technology will not obtain market demand, and the vehicle manufacturer will allocate demand orders according to the investment share $\Gamma_{r}^{j} / \sum_{j=1}^{b} \Gamma_{r}^{j}, 0<b<N$ (b is the number of enterprises implementing technology investment for product promotion, $0<b<N)$.

(iv) The vehicle manufacturer provides subsidies of promotion investment for $4 \mathrm{~S}$ stores and uses the same wholesale price for all 4 S. Since RFID investment can further expand the market and there is product promotion subsidy, rational retailers adopt this technology without hesitation. Therefore, we assume that the total market demand is $D\left(\Gamma_{r}\right)=\rho_{1} \sum_{j=1}^{N} \Gamma_{r}^{j}+d$. This is similar to the situation above. The profit of each $4 \mathrm{~S}$ store is common knowledge. All automotive $4 \mathrm{~S}$ stores play a static game of perfect information, and each will use RFID to maximize its own profit.

Proposition 3. The optimal RFID investment cost of automotive $4 S$ stores in decentralized decision-making is $\Gamma_{r j}^{*}=\Gamma_{s}^{*} / N$, if and only if the $4 S$ stores satisfy the following constrained equations:

$$
\begin{gathered}
\Gamma_{r 1}=\Gamma_{r 2}=\cdots=\Gamma_{r N} \\
\rho_{1}\left(k_{1}+N-1\right)\left(w-w_{m}\right)\left(\sum_{j=1}^{N} \Gamma_{r j}\right)^{k_{1}}-N(1-\alpha) \\
\times \sum_{j=1}^{N} \Gamma_{r j}+d\left(w-w_{m}\right)(N-1)=0 .
\end{gathered}
$$

The optimal RFID investment cost is a perfect Nash equilibrium.

4.4. Coordination in Decentralized Manufacturing System. To avoid impairing the enthusiasm of downstream supply chain members when the wholesale price is high, the upstream enterprise should give a high subsidy rate to encourage downstream ones' technical innovation. Certainly, when the wholesale price is low, upstream enterprises should appropriately reduce the subsidy rate to protect its own interest.

Proposition 4. The optimal contract $\left(w_{m}^{*}, \alpha^{*}\right)$ coordinating the vehicle manufacturer and automotive $4 S$ stores and the optimal profit of $4 S$ stores are given by

$$
\begin{gathered}
\alpha^{*}=1-\frac{w-w_{m}^{*}}{N \cdot \Gamma_{r}^{*}}\left[\rho_{1}\left(N-1+k_{1}\right) \Gamma_{r}^{* k_{1}}+(N-1) d\right], \\
w_{m}^{*}<w-\frac{N \Pi_{r j}+(1-\alpha) \Gamma_{r}^{*}}{\rho_{1} \Gamma_{r}^{* k_{1}}+d}, \\
\Pi_{r j}^{*}=\frac{1}{N}\left(w-w_{m}^{*}\right)\left[\rho_{1} \Gamma_{r}^{* k_{1}}+d\right]-\frac{1}{N}\left(1-\alpha^{*}\right) \Gamma_{r}^{*} .
\end{gathered}
$$

With the increase of $N$, the competition among automotive $4 \mathrm{~S}$ stores becomes fierce, thus increasing the minimum wholesale price while reducing its maximum, reducing the coordinated range of the wholesale price, and impairing $4 \mathrm{~S}$ stores' ability of bargaining. The profit of $4 \mathrm{~S}$ stores decreases progressively according to exponential law.

With the increase of $M$, the competition among components suppliers is increasingly fierce, and the maximum purchasing price decreases. As coordination becomes more and more difficult, the vehicle manufacturer will increase the minimum value of the purchasing price. The price will be stable at a certain point if $M$ reaches a certain value.

As can be seen from the analysis above, we find that the vehicle manufacturer should provide a high $R \& D$ subsidy rate to protect the enthusiasm of components suppliers when the purchasing price is low. However, when this price is high, for its own interest, the manufacturer should provide a low rate. RFID technology reduces the production cost of suppliers. The lower limit of purchasing price that can be accepted by suppliers decreases, and they improve their own endurance to low price and expand their profit space. This indicates the competitive advantage brought by the enterprises' technology innovation and lower production cost.

\section{Numerical Analysis}

Finally, a numerical example is taken to validate the rationality and feasibility of the theoretics and method. We insert the following constant values into the corresponding optimal expressions: $c_{s}=1.2 \times 10^{5}, w=2.5 \times 10^{5}, c_{m}=2 \times 10^{4}$, $w_{m}=1.9 \times 10^{5}$, and $p_{m}=1.35 \times 10^{5}$, which satisfy $p_{m}+c_{m}<w_{m}<w$ and $p_{m}>C\left(\Gamma_{s}\right)$. Additionally $k_{1} \in(0,1)$, $k_{2} \in(0,1), \rho_{1} \in(0,100)$, and $\rho_{2} \in(0,100)$.

The numerical analysis is carried out by taking the case study of applying RFID in automotive $4 \mathrm{~S}$ stores under the decentralized decision-making among supply chains. Figure 6 shows the variation of 4 S stores' profit under different quantity of stores. Figure 7 demonstrates that the variation tendency of $4 \mathrm{~S}$ stores' total profit changes with the fluctuation in market demand and competition level among various component suppliers. The relationship between RFID investment profit and sensitivity coefficients is described 


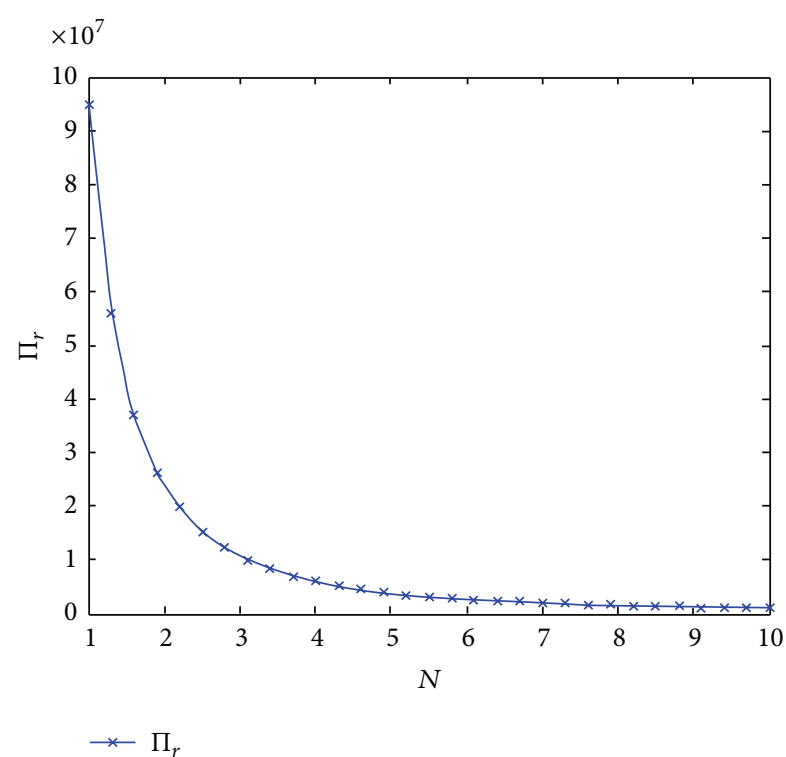

FIgURE 6: Variation of $4 S$ stores's profit $\Pi_{r}$ with the quantity of $4 S$ stores $N$.

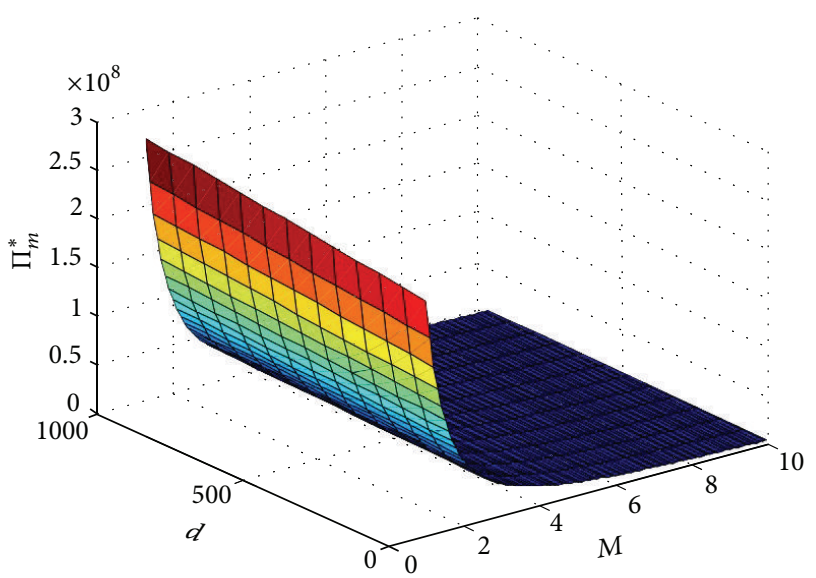

Figure 7: Variation of $\Pi_{m}^{*}$ with $d$ and $M$.

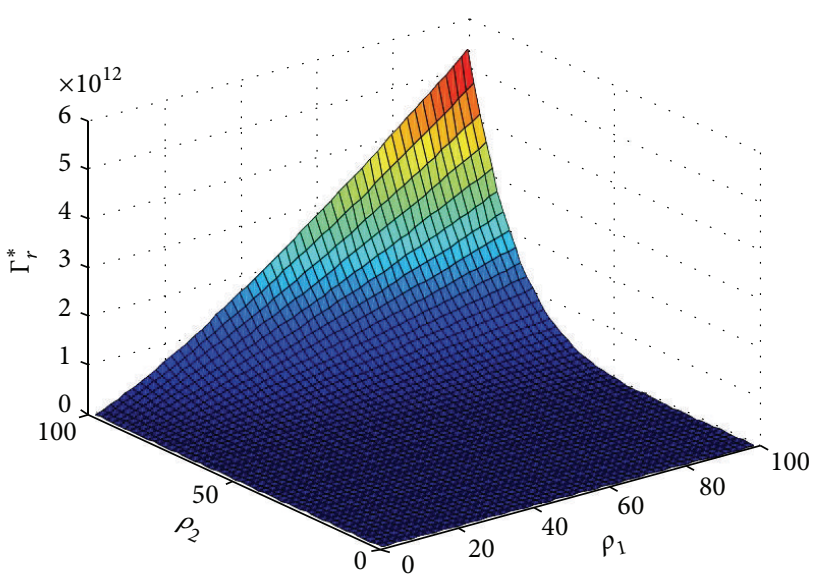

Figure 8: Variation of $\Pi_{r}^{*}$ with $\rho_{1}$ and $\rho_{2}$.

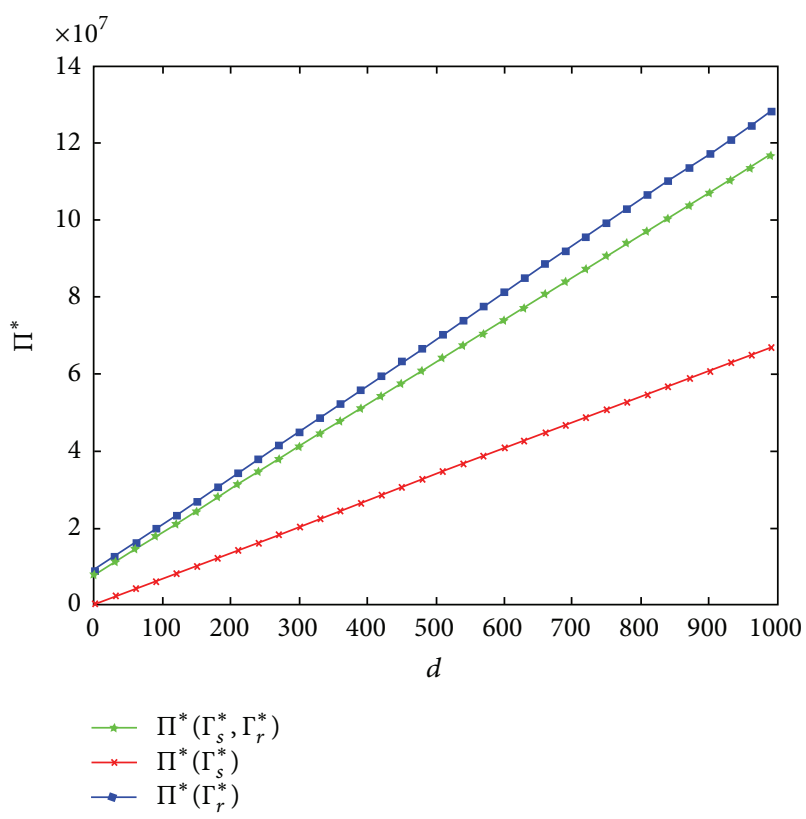

FIguRE 9: Variation of $\Pi^{*}\left(\Gamma_{s}^{*}, \Gamma_{r}^{*}\right), \Pi^{*}\left(\bar{\Gamma}_{s}^{*}\right)$, and $\Pi^{*}\left(\bar{\Gamma}_{r}^{*}\right)$ with $d$.

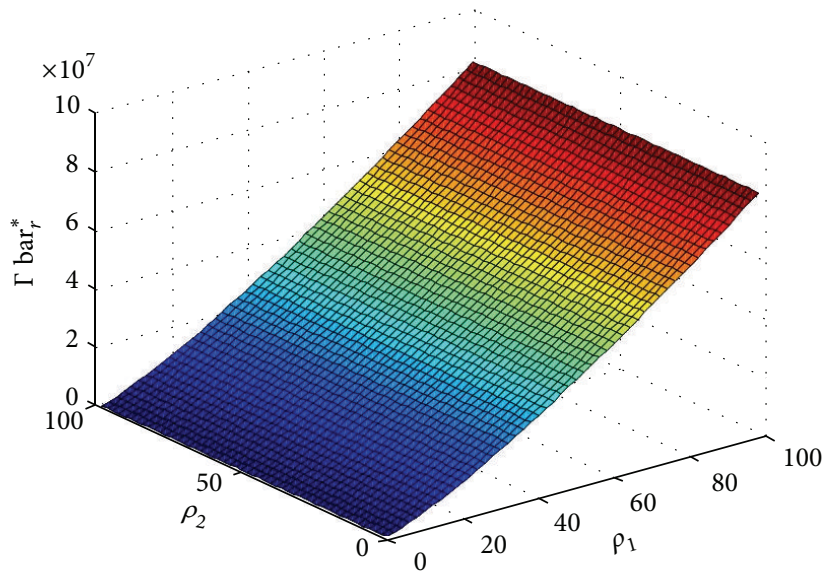

Figure 10: Variation of $\Pi^{*}\left(\Gamma_{s i}^{*}\right)$ with $d$ and $\theta$.

as in Figure 8. Figures 9 and 10 show the variation of overall optimal profit with RFID investment regarding the combination of different quantities of components suppliers and $4 \mathrm{~S}$ demands. The maximum profit of the manufacturer is irrelevant to the number of downstream partners; however, the greater the number of suppliers, the lower the maximum profit of the manufacturer. This is consistent with the actual result observed; that is, with a larger scale of the core enterprise and a great number of suppliers, the core enterprise has a strong ability of independent pricing in negotiation and obtains great profits.

This paper mainly studies the investment impact of RFID in the automobile manufacturing supply chain. Since it is hard to gain the cost of automobile parts and RFID equipment, as well as losses, specific RFID investment is empirically studied next. 


\section{Conclusion}

Wireless sensor network technology has been well recognized as an effective way to improve the efficiency of information acquisition, process, and exchange in manufacturing industries. RFID, as a typical WSN device, owns the ability to process real-time information in practical applications. However, RFID technology deployment is complex and requires certain investment. How to evaluate the feasibility of applying RFID in one enterprise is still not well addressed. The approach and technology proposed in this paper have important reference value for the application of WSN in the manufacturing field. Therefore, this paper is the first in the literature that demonstrates the bright future of applying RFID in automotive industry. With the increasing flexibility and make-to-order request in many industries, RFID will be used more throughout. These products have higher demand flexibility, obvious effect of promotion, high unit product cost, and great potential for cost reduction. The product information stored in RFID will accompany a vehicle in the supply chain, from manufacturing to sale, and then to after-sale service. The proposed RFID investment model in this paper could result in a high efficiency of the supply chain, that is, minimizing the operation cost while improving market share to the maximum extent. It could be successfully applied to virtually all critical products throughout their life cycle, that is, from the manufacturing period to the usage mature period. Meanwhile, it applies to the situation in which products provided by multiple suppliers are homogeneous.

This paper assumed the availability of complete information. However, the coordination of the supply chain in more complicated and practical situations, such as asymmetric information and uncertain environment, is not considered. Moreover, the model is not appropriate for quick response supply chain, aiming at rapidly responding to customer demand, and innovation supply chain emphasizing the satisfaction of customers' changing demands. All of these are the directions for future research.

\section{Appendix}

Proof of Proposition 1. Consider

$$
\begin{aligned}
\Pi\left(\Gamma_{s}, \Gamma_{r}\right)= & D\left(\Gamma_{r}\right) \cdot\left[w-c_{m}-C\left(\Gamma_{s}\right)\right]-\Gamma_{s}-\Gamma_{r} \\
= & \left(\rho_{1} \Gamma_{r}^{k_{1}}+d\right) \cdot\left[w-c_{m}-c_{s}-\rho_{2}\left(\frac{\Gamma_{s}}{\rho_{1} \Gamma_{r}^{k_{1}}+d}\right)^{k_{2}}\right] \\
& -\Gamma_{s}-\Gamma_{r} .
\end{aligned}
$$

The following can be obtained by derivation of $\Gamma_{s}$ and $\Gamma_{s}$ in the formula above:

$$
\frac{\partial \Pi\left(\Gamma_{s}, \Gamma_{r}\right)}{\partial \Gamma_{s}}=\rho_{2} k_{2} \Gamma_{s}^{\rho_{2}-1}\left(\rho_{1} \Gamma_{r}^{k_{1}}+d\right)^{1-k_{2}}-1,
$$

$$
\begin{aligned}
& \frac{\partial \Pi\left(\Gamma_{s}, \Gamma_{r}\right)}{\partial \Gamma_{r}}=\rho_{1} k_{1}\left(w-c_{m}-c_{s}\right) \Gamma_{r}^{\rho_{1}-1} \\
& +\rho_{1} \rho_{2} k_{1}\left(1-k_{2}\right)\left(\frac{\Gamma_{s}}{\rho_{1} \Gamma_{r}^{k_{1}}+d}\right)^{k_{2}} \Gamma_{r}^{\rho_{1}-1}-1, \\
& \frac{\partial \Pi\left(\Gamma_{s}, \Gamma_{r}\right)}{\partial \Gamma_{s} \partial \Gamma_{r}}=\frac{\partial \Pi\left(\Gamma_{s}, \Gamma_{r}\right)}{\partial \Gamma_{r} \partial \Gamma_{s}}=\rho_{1} \rho_{2} k_{1} k_{2}\left(1-k_{2}\right) \Gamma_{r}^{\rho_{1}-1} \Gamma_{s}^{\rho_{2}-1} \\
& \times\left(\rho_{1} \Gamma_{r}^{k_{1}}+d\right)^{-k_{2}} .
\end{aligned}
$$

Since $\partial^{2} \Pi\left(\Gamma_{s}, \Gamma_{r}\right) / \partial \Gamma_{r}^{2}<0\left(\partial^{2} \Pi\left(\Gamma_{s}, \Gamma_{r}\right) / \partial \Gamma_{s}^{2}\right)<0$, Hessian matrix of $\Pi\left(\Gamma_{s}, \Gamma_{r}\right)$ is always larger than 0 :

$$
\begin{aligned}
& \left|\begin{array}{ll}
\frac{\partial^{2} \Pi\left(\Gamma_{s}, \Gamma_{r}\right)}{\partial \Gamma_{r}^{2}} & \frac{\partial \Pi\left(\Gamma_{s}, \Gamma_{r}\right)}{\partial \Gamma_{r} \partial \Gamma_{s}} \\
\frac{\partial \Pi\left(\Gamma_{s}, \Gamma_{r}\right)}{\partial \Gamma_{s} \partial \Gamma_{r}} & \frac{\partial^{2} \Pi\left(\Gamma_{s}, \Gamma_{r}\right)}{\partial \Gamma_{s}^{2}}
\end{array}\right| \\
& =\left[\begin{array}{ll}
\rho_{1} k_{1}\left(k_{1}-1\right)\left(w-c_{m}-c_{s}\right) \Gamma_{r}^{\rho_{1}-2} \\
\quad+\rho_{1} \rho_{2} k_{1}\left(1-k_{2}\right)\left(k_{1}-1\right) \Gamma_{r}^{\rho_{1}-2} \cdot\left(\rho_{1} \Gamma_{r}^{k_{1}}+d\right)^{-k_{2}}
\end{array}\right] \\
& \quad\left[\rho_{2} k_{2}\left(k_{2}-1\right) \Gamma_{r}^{\rho_{2}-2}\left(\rho_{1} \Gamma_{r}^{k_{1}}+d\right)^{1-k_{2}}\right]>0 .
\end{aligned}
$$

Therefore, Hessian matrix of $\Pi\left(\Gamma_{s}, \Gamma_{r}\right)$ is negative definite and is a strictly concave function of $\left(\Gamma_{s}, \Gamma_{r}\right)$. To obtain maximum profit, RFID R\&D investment should satisfy $\partial^{2} \Pi\left(\Gamma_{s}, \Gamma_{r}\right) / \partial \Gamma_{r}^{2}=0$ and under the centralized decisionmaking.

Therefore, the following can be obtained:

$$
\begin{aligned}
\Gamma_{r}^{*}= & \left(\rho_{1} k_{1}\right)^{1 /\left(1-k_{1}\right)} \\
& \cdot\left[w-c_{m}-c+\left(1-k_{2}\right) \rho_{2}{ }^{1 /\left(1-k_{2}\right)} k_{2}{ }^{k_{2} /\left(1-k_{2}\right)}\right]^{1 /\left(1-k_{1}\right)} .
\end{aligned}
$$

That is, if the $4 \mathrm{~S}$ shops invest RFID $\Gamma_{r}^{*}$ to make a good promotion and the component suppliers research and develop RFID technology and put into investment cost $\Gamma_{s}^{*}$, the overall supply chain system can get the optimal profit $\Pi^{*}\left(\Gamma_{s}^{*}, \Gamma_{r}^{*}\right)$.

\section{Nomenclature}

$D$ : The total demand of the customer

$d$ : The market demand when the automotive $4 \mathrm{~S}$ shops does not implement RFID investment, $d>0$

$C$ : The cost function of unit product

$c_{s}$ : The product cost without application of RFID in the components suppliers

$w$ : The selling price of unit product

$c_{m}$ : The production cost of the vehicle manufacturer per unit (excluding purchase cost of raw material) 
$p_{m}$ : The price of unit raw materials (or semifinished products, components, and parts) of the suppliers

$w_{m}$ : The wholesale price of the vehicle manufacturer per item

$\Gamma_{s}: \quad$ RFID investment cost of the components suppliers, $\Gamma_{s} \geq 0$

$\Gamma_{r}$ : RFID investment cost of the automotive $4 \mathrm{~S}$ stores, $\Gamma_{r} \geq 0$

$\alpha$ : The subsidy rate from vehicle manufacturer to $4 \mathrm{~S}$ stores, $0<\alpha<1$

$\beta$ : The subsidy rate provided by vehicle manufacturer's R\&D incentive to components suppliers, $0<\beta<1$

$\theta$ : The technical success rate, $0<\theta<1$.

\section{Conflict of Interests}

The authors declare that there is no conflict of interests regarding the publication of this paper.

\section{Acknowledgment}

This research was supported by the University of Macau (Grant nos. MYRG153(Y1-L2)-FST11-YZX and MYRG079 (Y1-L2)-FST13-YZX).

\section{References}

[1] A. Sarac, N. Absi, and S. Dauzère-Pérès, "A literature review on the impact of RFID technologies on supply chain management," International Journal of Production Economics, vol. 128, no. 1, pp. 77-95, 2010.

[2] G. Q. Huang, Y. F. Zhang, and P. Y. Jiang, "RFID-based wireless manufacturing for walking-worker assembly islands with fixed-position layouts," Robotics and Computer-Integrated Manufacturing, vol. 23, no. 4, pp. 469-477, 2007.

[3] G. Q. Huang, Y. F. Zhang, and P. Y. Jiang, "RFID-based wireless manufacturing for real-time management of job shop WIP inventories," The International Journal of Advanced Manufacturing Technology, vol. 36, no. 7-8, pp. 752-764, 2008.

[4] H.-B. Jun, J.-H. Shin, D. Kiritsis, and P. Xirouchakis, "System architecture for closed-loop PLM," International Journal of Computer Integrated Manufacturing, vol. 20, no. 7, pp. 684-698, 2007.

[5] M.-C. Tsai, W. Lee, and H.-C. Wu, "Determinants of RFID adoption intention: evidence from Taiwanese retail chains," Information and Management, vol. 47, no. 5-6, pp. 255-261, 2010.

[6] R.-S. Chen and M. Tu, "Development of an agent-based system for manufacturing control and coordination with ontology and RFID technology," Expert Systems with Applications, vol. 36, no. 4, pp. 7581-7593, 2009.

[7] H. K. H. Chow, K. L. Choy, W. B. Lee, and K. C. Lau, "Design of a RFID case-based resource management system for warehouse operations," Expert Systems with Applications, vol. 30, no. 4, pp. 561-576, 2006.

[8] H. K. H. Chow, K. L. Choy, W. B. Lee, and F. T. S. Chan, "Integration of web-based and RFID technology in visualizing logistics operations: a case study," Supply Chain Management, vol. 12, no. 3, pp. 221-234, 2007.
[9] J. M. Ko, C. Kwak, Y. Cho, and C. O. Kim, "Adaptive product tracking in RFID-enabled large-scale supply chain," Expert Systems with Applications, vol. 38, no. 3, pp. 1583-1590, 2011.

[10] J. J. Roh, A. Kunnathur, and M. Tarafdar, "Classification of RFID adoption: an expected benefits approach," Information \& Management, vol. 46, no. 6, pp. 357-363, 2009.

[11] S. Kim and G. Garrison, "Understanding users' behaviors regarding supply chain technology: determinants impacting the adoption and implementation of RFID technology in South Korea," International Journal of Information Management, vol. 30, no. 5, pp. 388-398, 2010.

[12] M.-C. Kim, C. O. Kim, S. R. Hong, and I.-H. Kwon, "Forwardbackward analysis of RFID-enabled supply chain using fuzzy cognitive map and genetic algorithm," Expert Systems with Applications, vol. 35, no. 3, pp. 1166-1176, 2008.

[13] R. Goel, "Managing RFID consumer privacy and implementation barriers," Information Systems Security, vol. 16, no. 4, pp. 217-223, 2007.

[14] E. Bottani and A. Rizzi, "Economical assessment of the impact of RFID technology and EPC system on the fast-moving consumer goods supply chain," International Journal of Production Economics, vol. 112, no. 2, pp. 548-569, 2008.

[15] Y. Z. Mehrjerdi, "RFID-enabled supply chain systems with computer simulation," Assembly Automation, vol. 29, no. 2, pp. 174-183, 2009.

[16] E. W. T. Ngai, T. C. E. Cheng, S. Au, and K.-H. Lai, "Mobile commerce integrated with RFID technology in a container depot," Decision Support Systems, vol. 43, no. 1, pp. 62-76, 2007.

[17] D. Mánik, L. Tóth, and P. Döbrössy, "Analysis of RFId application through an automotive supplier's production processes," in Proceedings of the 3rd International Symposium on Computational Intelligence and Intelligent Informatics (ISCIII '07), pp. 177-181, IEEE, March 2007.

[18] H. K. H. Chow, K. L. Choy, and W. B. Lee, "Design of a RFIDbased resource management system for warehouse operation," in Proceedings of the 3rd IEEE International Conference on Industrial Informatics (INDIN '05), pp. 785-790, August 2005.

[19] M. Schmidt and H.-W. Ziemba, "RFID in the automotive industry - a standards based approach towards on-tag data sharing in cross-company logistics," in Proceedings of the 5th MMS-Technologies, Applications and Services in Support of Mobile Collaboration (MMS '10), pp. 167-173, February 2010.

[20] G. Q. Huang, T. Qu, Y. Zhang, and H. D. Yang, "RFID-enabled product-service system for automotive part and accessory manufacturing alliances," International Journal of Production Research, vol. 50, no. 14, pp. 3821-3840, 2012.

[21] S. Kumar, B. B. Kadow, and M. K. Lamkin, "Challenges with the introduction of radio-frequency identification systems into a manufacturer's supply chain-a pilot study," Enterprise Information Systems, vol. 5, no. 2, pp. 235-253, 2011.

[22] G. M. Gaukler, R. W. Seifert, and W. H. Hausman, "Item-level RFID in the retail supply chain," Production and Operations Management, vol. 16, no. 1, pp. 65-76, 2007.

[23] M. Tajima, "Strategic value of RFID in supply chain management," Journal of Purchasing and Supply Management, vol. 13, no. 4, pp. 261-273, 2007.

[24] Y. T. Leung, F. Cheng, Y. M. Lee, and J. J. Hennessy, "A tool set for exploring the value of RFID in a supply chain," in Trends in Supply Chain Design and Management, pp. 49-70, Springer, Berlin, Germany, 2007. 
[25] C. L. Munson and M. J. Rosenblatt, "Coordinating a three-level supply chain with quantity discounts," IIE Transactions, vol. 33, no. 5, pp. 371-384, 2001.

[26] L. Cassivi, L. A. Lefebvre, and E. Lefebvre, "Multi-layered collaborative procurement planning and optimization," in Proceedings of the IEEE International Engineering Management Conference, pp. 278-282, August 2000.

[27] R. Lal, "Improving channel coordination through franchising," Marketing Science, vol. 9, no. 4, pp. 299-318, 1990.

[28] R. Anupindi, Y. Bassok, and E. Zemel, "A general framework for the study of decentralized distribution systems," Manufacturing and Service Operations Management, vol. 3, no. 4, pp. 349-368, 2001.

[29] H. Gurnani and Y. Gerchak, "Coordination in decentralized assembly systems with uncertain component yields," European Journal of Operational Research, vol. 176, no. 3, pp. 1559-1576, 2007.

[30] F. Bernstein, F. Chen, and A. Federgruen, "Vendor managed inventories and supply chain coordination: the case with one supplier and competing retailers," Tech. Rep., Duke University working paper, 2002. 


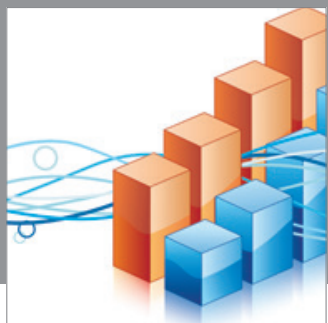

Advances in

Operations Research

mansans

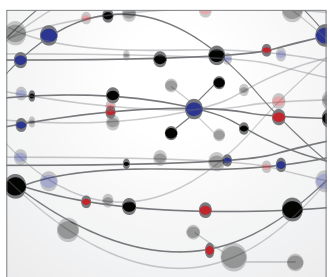

The Scientific World Journal
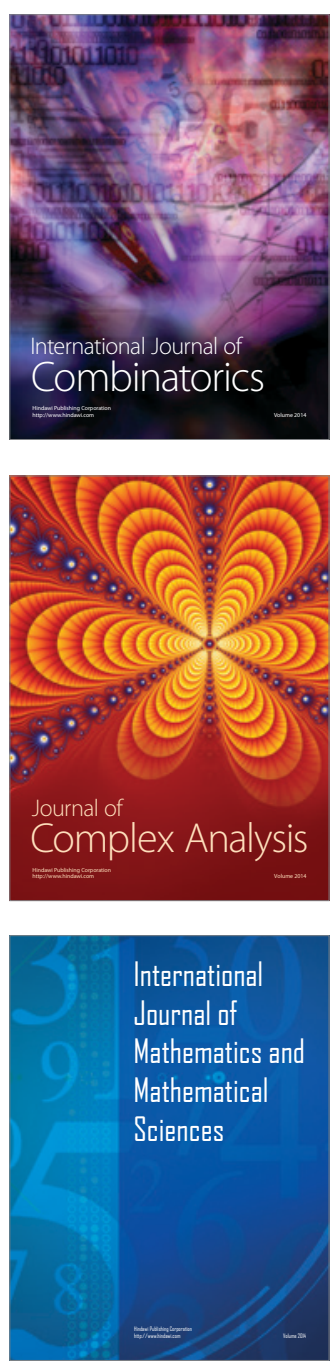
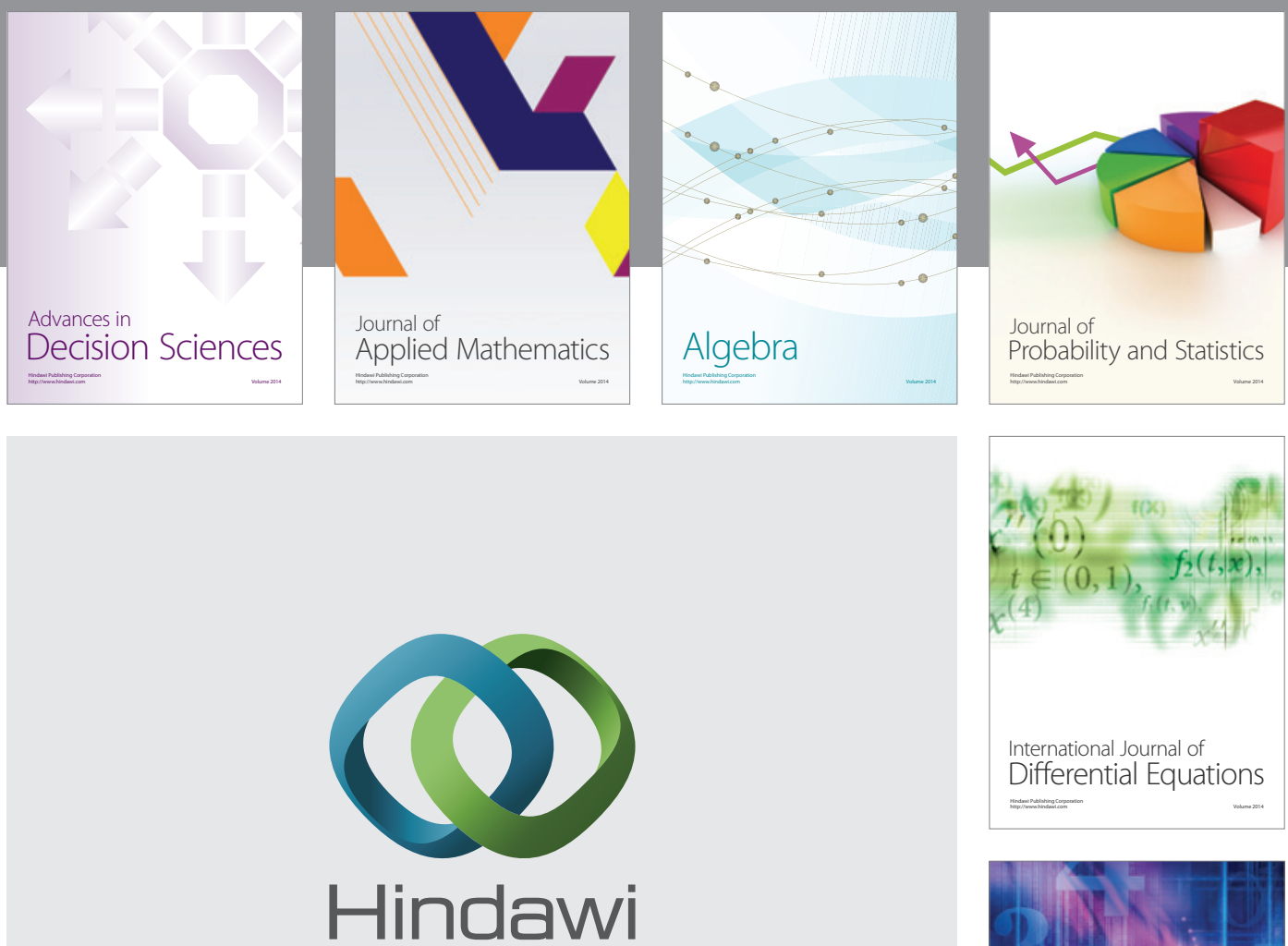

Submit your manuscripts at http://www.hindawi.com
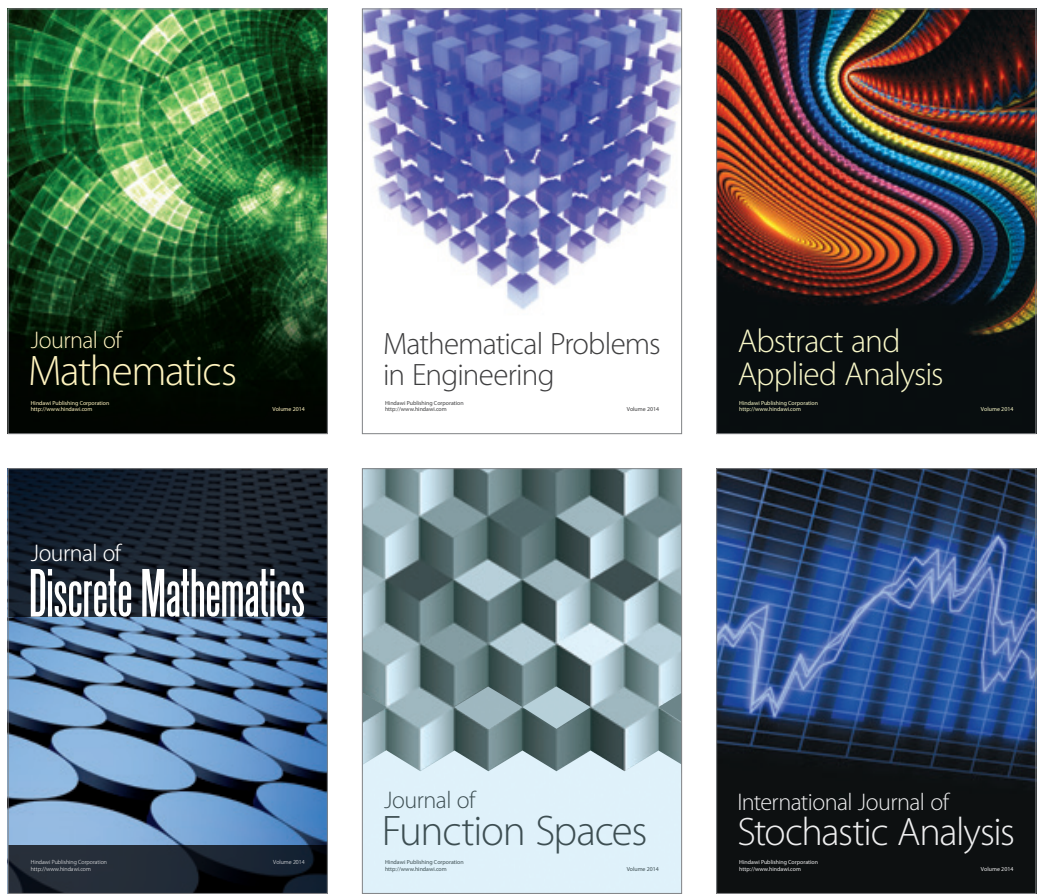

Journal of

Function Spaces

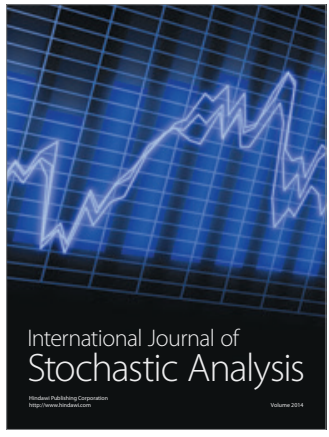

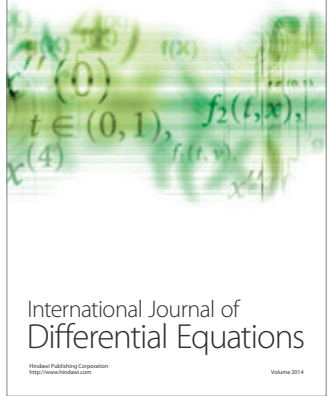
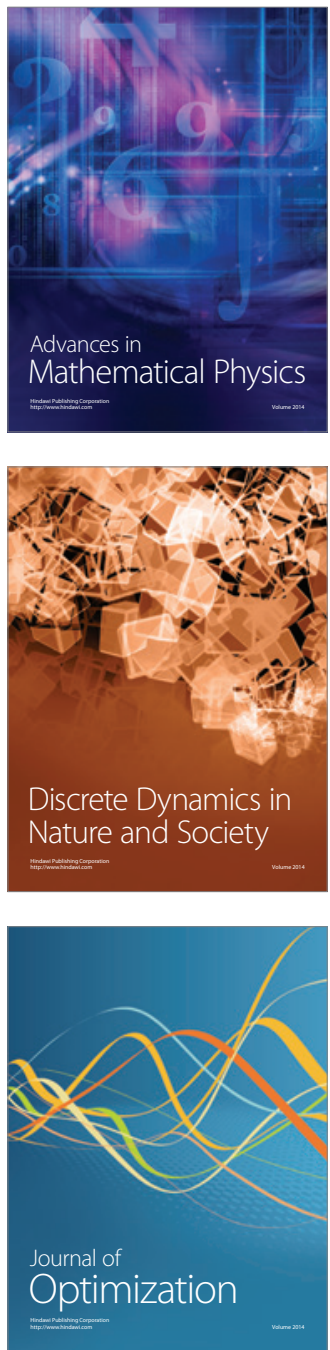